\title{
Bacterial RNA and small antiviral compounds activate caspase-1 through cryopyrin/Nalp3
}

\author{
Thirumala-Devi Kanneganti ${ }^{1}$, Nesrin Özören ${ }^{1}$, Mathilde Body-Malapel ${ }^{1}$, Amal Amer ${ }^{1}$, Jong-Hwan Park ${ }^{1}$, \\ Luigi Franchi ${ }^{1}$, Joel Whitfield ${ }^{1}$, Winfried Barchet ${ }^{2}$, Marco Colonna ${ }^{2}$, Peter Vandenabeele ${ }^{3}$, John Bertin ${ }^{4}{ }$, \\ Anthony Coyle ${ }^{4} \dagger$, Ethan P. Grant ${ }^{4} \dagger$, Shizuo Akira ${ }^{5} \&$ Gabriel Núñez ${ }^{1}$
}

\begin{abstract}
Missense mutations in the CIAS1 gene cause three autoinflammatory disorders: familial cold autoinflammatory syndrome, Muckle-Wells syndrome and neonatal-onset multiple-system inflammatory disease ${ }^{1}$. Cryopyrin (also called Nalp3), the product of CIAS1, is a member of the NOD-LRR protein family that has been linked to the activation of intracellular host defence signalling pathways ${ }^{2,3}$. Cryopyrin forms a multi-protein complex termed 'the inflammasome', which contains the apoptosisassociated speck-like protein (ASC) and caspase-1, and promotes caspase- 1 activation and processing of pro-interleukin (IL)- $1 \beta$ (ref. 4). Here we show the effect of cryopyrin deficiency on inflammasome function and immune responses. Cryopyrin and ASC are essential for caspase-1 activation and IL-1 $\beta$ and IL-18 production in response to bacterial RNA and the imidazoquinoline compounds $\mathrm{R} 837$ and $\mathrm{R} 848$. In contrast, secretion of tumournecrosis factor- $\alpha$ and IL-6, as well as activation of NF- $\mathrm{KB}$ and mitogen-activated protein kinases (MAPKs) were unaffected by cryopyrin deficiency. Furthermore, we show that Toll-like receptors and cryopyrin control the secretion of IL-1 $\beta$ and IL-18 through different intracellular pathways. These results reveal a critical role for cryopyrin in host defence through bacterial RNA-mediated activation of caspase-1, and provide insights regarding the pathogenesis of autoinflammatory syndromes.
\end{abstract}

To define the role of cryopyrin in inflammatory responses, we generated cryopyrin-deficient mice by homologous recombination using a targeting construct to replace exons I and II of the cryopyrin gene (Cias1), which encode the pyrin domain of cryopyrin that is essential for effector function of the protein (Supplementary Fig. 1). Cias $1^{-1-}$ mice were fertile and appeared healthy when housed in a standard specific pathogen-free environment.We initially investigated the role of cryopyrin in caspase-1-dependent IL-1 $\beta$ secretion using thioglycollate-elicited peritoneal macrophages and bone marrow-derived macrophages (BMDMs) and multiple bacterial and synthetic ligands. Stimulation of peritoneal macrophages or BMDMs with several TLR2 and TLR4 agonists, including diacylated (Pam $\left.{ }_{2} \mathrm{CGDPKHPHSF}\right)$ and triacylated $\left(\mathrm{Pam}_{3} \mathrm{CSK}_{4}\right)$ synthetic lipopeptides, lipoteichoic acid, highly purified lipopolysaccharide (LPS) and lipid A induced comparable levels of IL-1 $\beta$ in wild-type and Cias $^{-1-}$ macrophages (Fig. 1a and Supplementary Fig. 2). Similar results were obtained when macrophages were stimulated with bacterial ligands and treated briefly with ATP (Supplementary Fig. 3), a signal that enhances the secretion of IL-1 $\beta$ in pre-stimulated macrophages ${ }^{5}$. Incubation of macrophages with muramyl dipeptide (MDP) did not induce secretion of IL-1 $\beta$ above background levels in wild-type and Cias1 ${ }^{-1-}$ macrophages, even after addition of ATP (Fig. 1a; see also Supplementary Fig. 3). Furthermore, production of interferon- $\alpha$ induced by several viruses was unimpaired in macrophages and dendritic cells from Cias $1^{-1-}$ mice (Supplementary Fig. 4).

Notably, secretion of IL-1 $\beta$ and IL-18 induced by the low molecular weight imidazoquinoline compounds imiquimod (R837) and resiquimod (R848), which are known to activate pro-inflammatory responses in the mouse through TLR7 (refs 6, 7), was abrogated in both peritoneal macrophages and BMDMs from Cias ${ }^{-9-}$ mice (Fig. 1a-c). In contrast, cryopyrin was dispensable for the production of the pro-inflammatory cytokines tumour-necrosis factor- $\alpha$ (TNF- $\alpha$ ) and IL-6 induced by stimulation with R837 (Fig. 1c). These results indicate that cryopyrin is specifically required for the secretion of IL-1 $\beta$ and IL-18 induced by the synthetic molecules R837 and R848.

The induction of IL-1 $\beta$ secretion is thought to involve the upregulation of pro-IL- $1 \beta$ through transcriptional mechanisms via $\mathrm{NF}-\kappa \mathrm{B}$, followed by a second stimulus that leads to the activation of caspase-1, processing of pro-IL-1 $\beta$ and release of mature IL-1 $\beta$ (refs 5, 8). We found that stimulation with R837 induced comparable levels of NF-кB, extracellular signal-regulated kinase (ERK) and p38 activation in wild-type and Cias1 ${ }^{-1-}$ macrophages (Fig. 2a). In contrast, activation of NF- $\mathrm{B}$ and MAPKs was abolished in TLR7and MyD88-deficient macrophages (Fig. 2b; see also Supplementary Fig. 5), consistent with previous results ${ }^{6}$. Importantly, proteolytic processing of pro-caspase- 1 was induced in wild-type macrophages by both R837 and R848, as determined by detection of the mature $20-\mathrm{kDa}$ subunit of caspase-1 (Fig. 2c). Such activation of caspase-1 was abrogated in macrophages lacking cryopyrin (Fig. 2c) or ASC (Fig. 2e), an adaptor that links cryopyrin to caspase-1 (refs 4, 9). In contrast, activation of caspase-1 was unimpaired in Cias1 $1^{-1-}$ macrophages in response to LPS and lipid A (Fig. 2d), further indicating that the ligand-recognition function of cryopyrin is highly specific. In our hands, MDP did not induce proteolytic processing of pro-caspase-1 in mouse macrophages (Fig. 2d), consistent with its inability to induce IL-1 $\beta$ secretion (Fig. 1a). Notably, activation of caspase- 1 induced by R837 proceeded normally in TLR7- or MyD88deficient macrophages (Fig. 2f, g). These results demonstrate that cryopyrin is essential for caspase-1 processing, independent of NF-кB and MAPK activation in response to R837 and R848. Furthermore, TLR7 and MyD88 are required for NF-кB and MAPK activation but are dispensable for caspase- 1 activation.

Structurally, R837 and R848 resemble purine bases ${ }^{10}$, suggesting

${ }^{1}$ University of Michigan Medical School, Department of Pathology and Comprehensive Cancer Center, Ann Arbor, Michigan 48109, USA. ${ }^{2}$ Department of Pathology and Immunology, Washington University School of Medicine, St. Louis, Missouri 63110, USA. ${ }^{3}$ Department of Molecular Biomedical Research, Ghent University, Zwijnaarde-Gent B-9052, Belgium. ${ }^{4}$ Millennium Pharmaceuticals Inc., Cambridge, Massachusetts 02139, USA. ${ }^{5}$ Department of Host Defense, Research Institute for Microbial Diseases, Osaka University, 3-1 Yamada-oka, Suita, Osaka 565-0871, Japan. †Present addresses: Synta Pharmaceuticals, 45 Hartwell Avenue, Lexington, Massachusetts 02421, USA (J.B. and E.P. G.); Medlmmune Inc., 1 Medlmmune Way, Gaithersburg, Maryland 20878, USA (A.C.). 

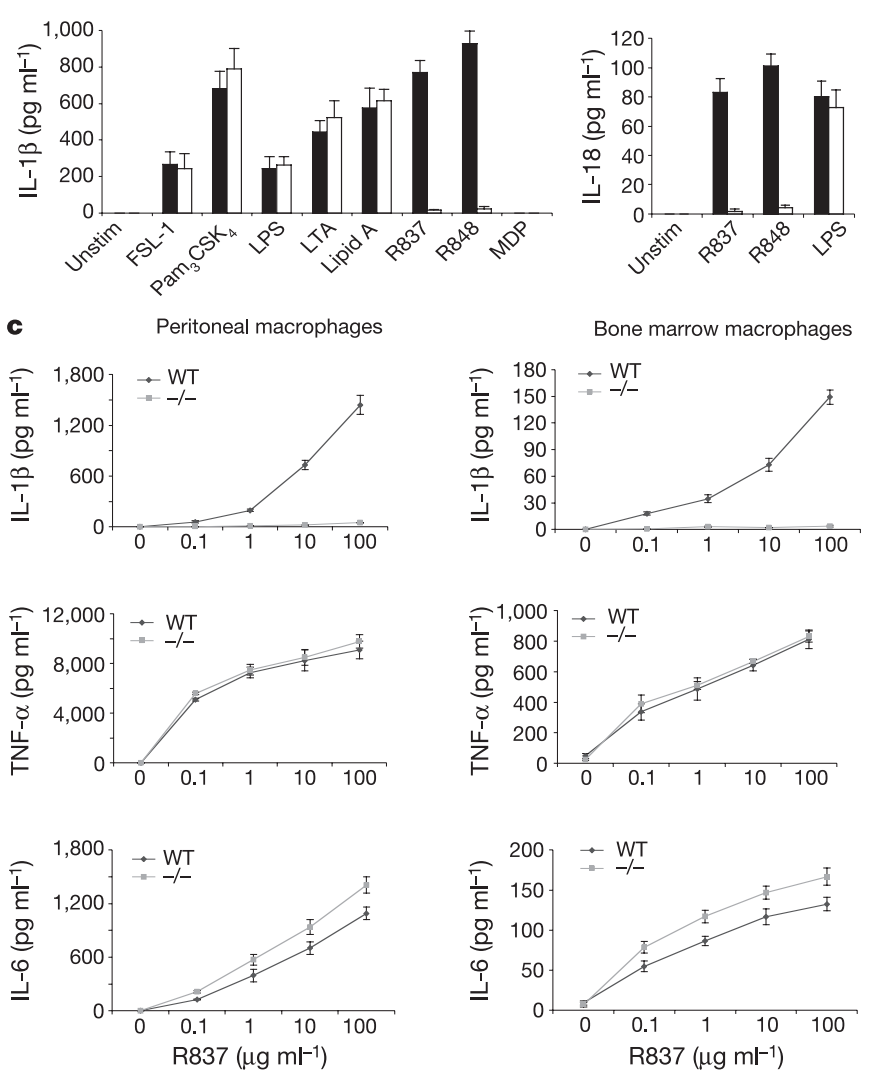

Figure 1 | Cryopyrin is required for IL-1 $\beta$ and IL-18 secretion in response to imidazoquinoline compounds R837 and R848. a, b, Peritoneal macrophages (a) and BMDMs (b) from wild-type (black bars) or Cias $1^{-1-}$ mice (white bars) were stimulated as indicated for $24 \mathrm{~h}$, and cell-free supernatants were analysed by ELISA. LA, lipid A; LTA, lipoteichoic acid; FSL-1, Pam2CGDPKHPHSF. c, Peritoneal macrophages (left panels) and BMDMs (right panels) were stimulated with the indicated concentrations of R837 for $24 \mathrm{~h}$, and cell-free supernatants were analysed by ELISA for production of IL-1 $\beta$ (top), TNF- $\alpha$ (middle) and IL-6 (bottom). WT, wild type; $-/-$ Cias $^{-/-}$. Error bars represent the standard deviation of triplicate cultures. Results are representative of at least three separate experiments.

that the natural ligand of cryopyrin could be DNA or RNA. Secretion of IL- $1 \beta$ and IL-18 was induced by Escherichia coli RNA in wild-type and Cias $1^{+/-}$macrophages, but was abolished in Cias $1^{-1-}$ macrophages (Fig. 3a and Supplementary Fig. 6). Treatment with chloroquine did not affect the production of IL- $1 \beta$ induced by bacterial RNA (Supplementary Fig. 7). E. coli RNA induced rapid activation of caspase-1 in wild-type but not in Cias $1^{-1-}$ macrophages (Fig. 3b). As we found with E. coli RNA, stimulation with total RNA from two different bacteria (Listeria monocytogenes and Legionella pneumophila), but not total RNA from mouse liver, induced activation of caspase-1 in wild-type but not in Cias $1^{-1-}$ macrophages (Fig. 3c, d). Treatment of the RNA preparations with RNase abolished their ability to induce caspase-1 activation (Fig. 3d), indicating that RNA, but not a contaminating product, triggers caspase- 1 activation. Furthermore, secretion of IL-1 $\beta$ and processing of pro-caspase-1 induced by bacterial RNA was abrogated in macrophages lacking ASC, but was unimpaired in TLR7- or MyD88-deficient macrophages (Fig. 3e and Supplementary Fig. 8). These results show that bacterial RNA activates caspase- 1 and IL-1 $\beta$ secretion, and that these events are mediated through cryopyrin and ASC, and are independent of TLR7 and MyD88.

Mononuclear cells from patients with autoinflammatory syndromes spontaneously secrete IL-1 $\beta$ and IL-18, and show enhanced a

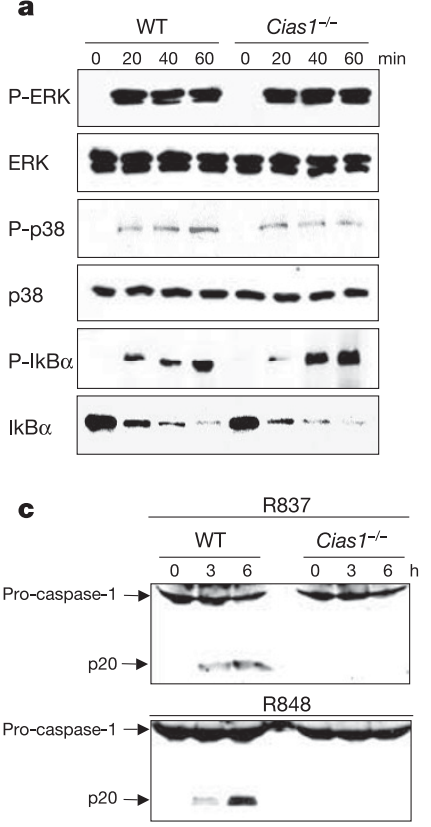

b

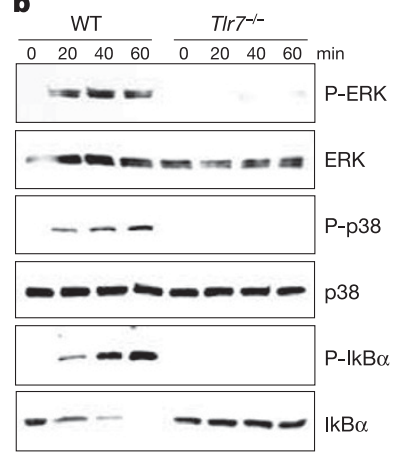

e
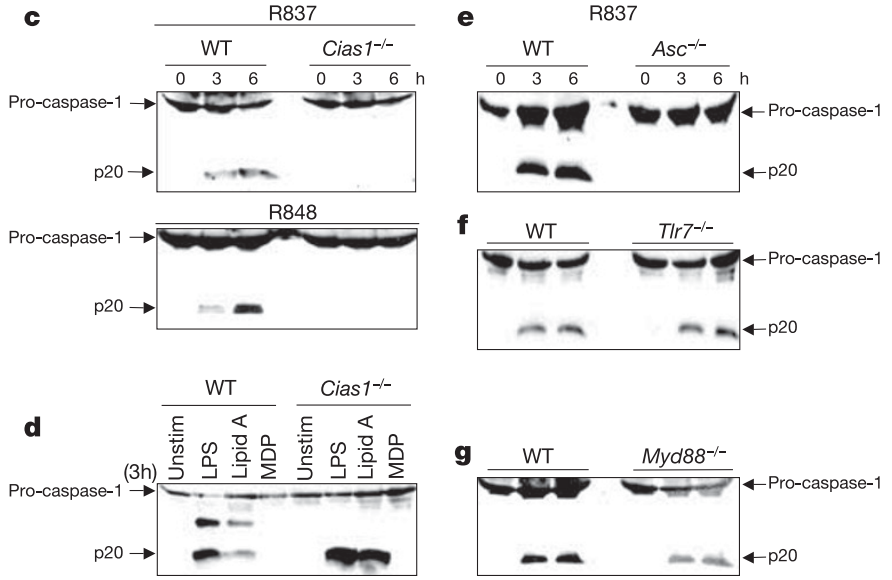

Figure 2 | Caspase-1 processing and NF- $\mathrm{kB}$ activation in mutant macrophages stimulated with $\mathbf{R 8 3 7}$ or R848. a, b, BMDMs from wild-type and Cias $1^{-1-}$ mice (a) or wild-type and $\operatorname{Tr} l 7^{-1-}$ mice (b) were stimulated with R837 (5 $\left.\mu \mathrm{g} \mathrm{ml}^{-1}\right)$ for the indicated times, and extracts were immunoblotted with antibodies that recognize phosphorylated (P-)ERK, $\mathrm{p} 38, \mathrm{IkB} \alpha$ and total protein. $\mathrm{IkB} \alpha$ phosphorylation can be used as a measure of NF-kB activation. c-g, BMDMs from wild-type and the indicated mutant mice were stimulated with $\mathrm{R} 837\left(5 \mu \mathrm{g} \mathrm{ml}^{-1}\right)$ or $\mathrm{R} 848\left(5 \mu \mathrm{g} \mathrm{ml}^{-1}\right)(\mathbf{c}, \mathbf{e}-\mathbf{g})$, LPS, lipid A (LA) or MDP $\left(10 \mu \mathrm{g} \mathrm{ml}^{-1}\right)$ (d). Cell extracts were immunoblotted with an antibody against caspase-1. Arrows denote pro-caspase- 1 and its processed p20 subunit.

production of IL-1 $\beta$ and IL-18 in response to low amounts of LPS ${ }^{4,11}$. This is consistent with the observation that disease-associated cryopyrin mutations show constitutive activity ${ }^{9}$. We therefore examined the ability of low doses of LPS to cooperate with low amounts of various microbial ligands in the production of IL-1 $\beta$. LPS synergized with R837, but not with lipopeptides, lipoteichoic acid, lipid A, flagellin or CpG oligodeoxynucleotide for the secretion of IL-1 $\beta$ (Fig. 4a). Such enhancement of LPS-mediated IL-1 $\beta$ production by $\mathrm{R} 837$ was abrogated in Cias $^{-1-}$ macrophages (Fig. 4a). The susceptibility to high doses of highly purified LPS induced comparable lethality in wild-type and Cias $1^{-1-}$ mice (Supplementary Fig. 9). The synergy between LPS and R837 might be explained, at least in part, by the ability of LPS to induce cryopyrin expression ${ }^{12}$. Consistent with our in vitro results, co-administration of R837 and LPS to mice induced higher levels of IL-1 $\beta$ in serum than injection of R837 or LPS alone (Fig. 4b). Furthermore, the enhancement of the LPS response by R837 was abolished in Cias $1^{-1-}$ mice (Fig. 4b). The serum levels of IL- 6 and TNF- $\alpha$ were also enhanced by co-injection of LPS and R837 when compared to those observed after administration of each molecule alone (Fig. 4c, d). Moreover, reduced levels of IL-6 and TNF- $\alpha$ were detected in the serum of Cias $^{-1-}$ mice after stimulation with LPS plus R837 (Fig. 4c, d), presumably owing to the induction of IL- 6 and TNF- $\alpha$ by IL-1 $\beta$ and/or IL-18 in $v i v o^{13}$.

These studies show that cryopyrin has an essential role in the secretion of IL-1 $\beta$ and IL-18 by controlling the activation of 

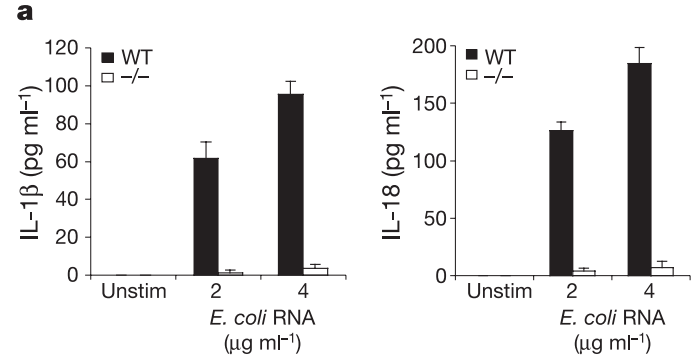

b
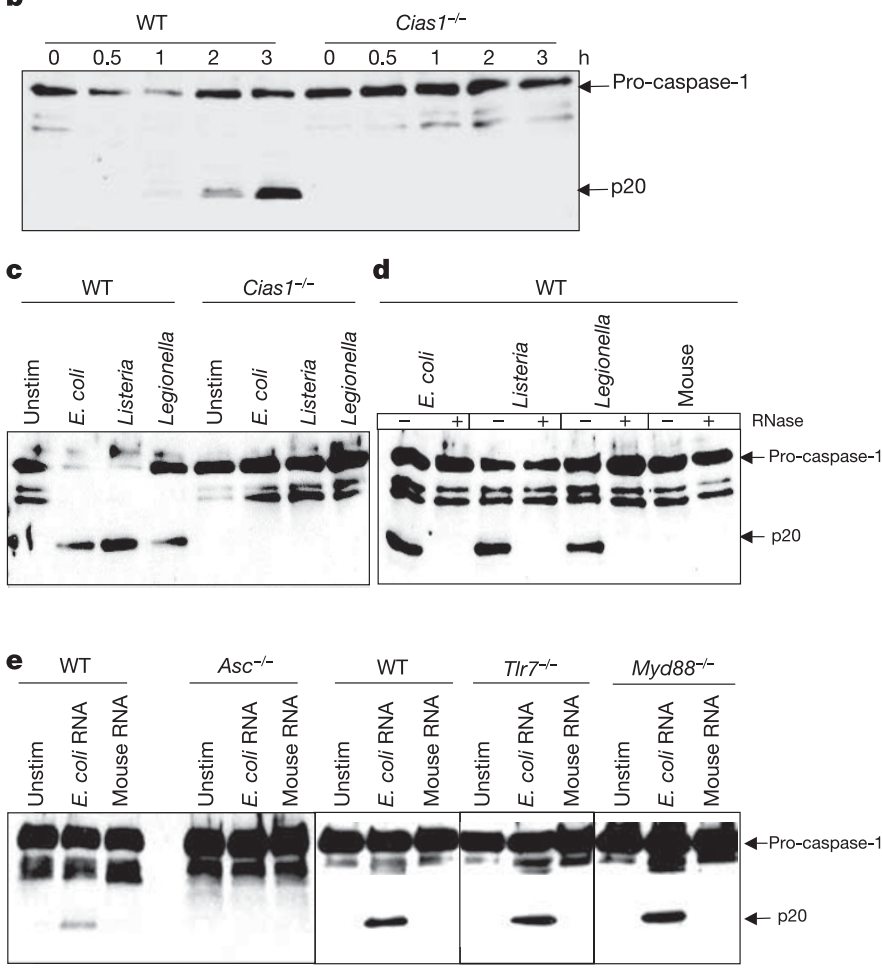

Figure 3 Cryopyrin is essential for activation of caspase-1 in response to bacterial RNA. a, BMDMs from wild-type (black bars) or Cias $1^{-1-}$ mice (white bars) were stimulated as indicated, and cell-free supernatants were analysed by ELISA for production of IL-1 $\beta$ or IL-18. b-d, BMDMs from wild-type and Cias $1^{-1-}$ mice were stimulated with RNA purified from $E$. coli (b) or the indicated bacteria $(\mathbf{c})$ with $(+)$ or without $(-)$ RNase digestion (d), and cell extracts were immunoblotted with an antibody against caspase1. e, BMDMs from wild-type and $A s c^{-1-}, T l r 7^{-1-}$ and $M y d 88^{-1-}$ mice were stimulated with purified RNA from E. coli or mouse liver for $3 \mathrm{~h}$.

pro-caspase-1 in response to bacterial RNA or the synthetic compounds R837 and R848. We provide evidence that secretion of IL- $1 \beta$ and IL-18 is regulated by separate signalling pathways that are independently controlled by TLR and NOD-LRR proteins. Previous studies, using an overexpression system in human HEK293 cells, have suggested that MDP mediates cryopyrin-mediated activation of caspase-1 and maturation of pro-IL-1 $\beta$ (ref. 14). We found no evidence that MDP induces the activation of caspase- 1 or the release of IL- $1 \beta$ in mouse macrophages, consistent with previous results ${ }^{15}$. Our studies, however, do not rule out the possibility that cryopyrin responds to MDP under certain conditions in the mouse and/or human system.

Our results indicate that TLRs and cryopyrin are involved in the activation of immune responses induced by the same or similar microbial structures ${ }^{6,16-18}$. Bacterial RNA might be derived from phagocytosed bacteria or lysis of bacteria in the extracellular space and transported into the host cytosol, leading to cryopyrin recognition and activation. The mechanism by which cryopyrin and
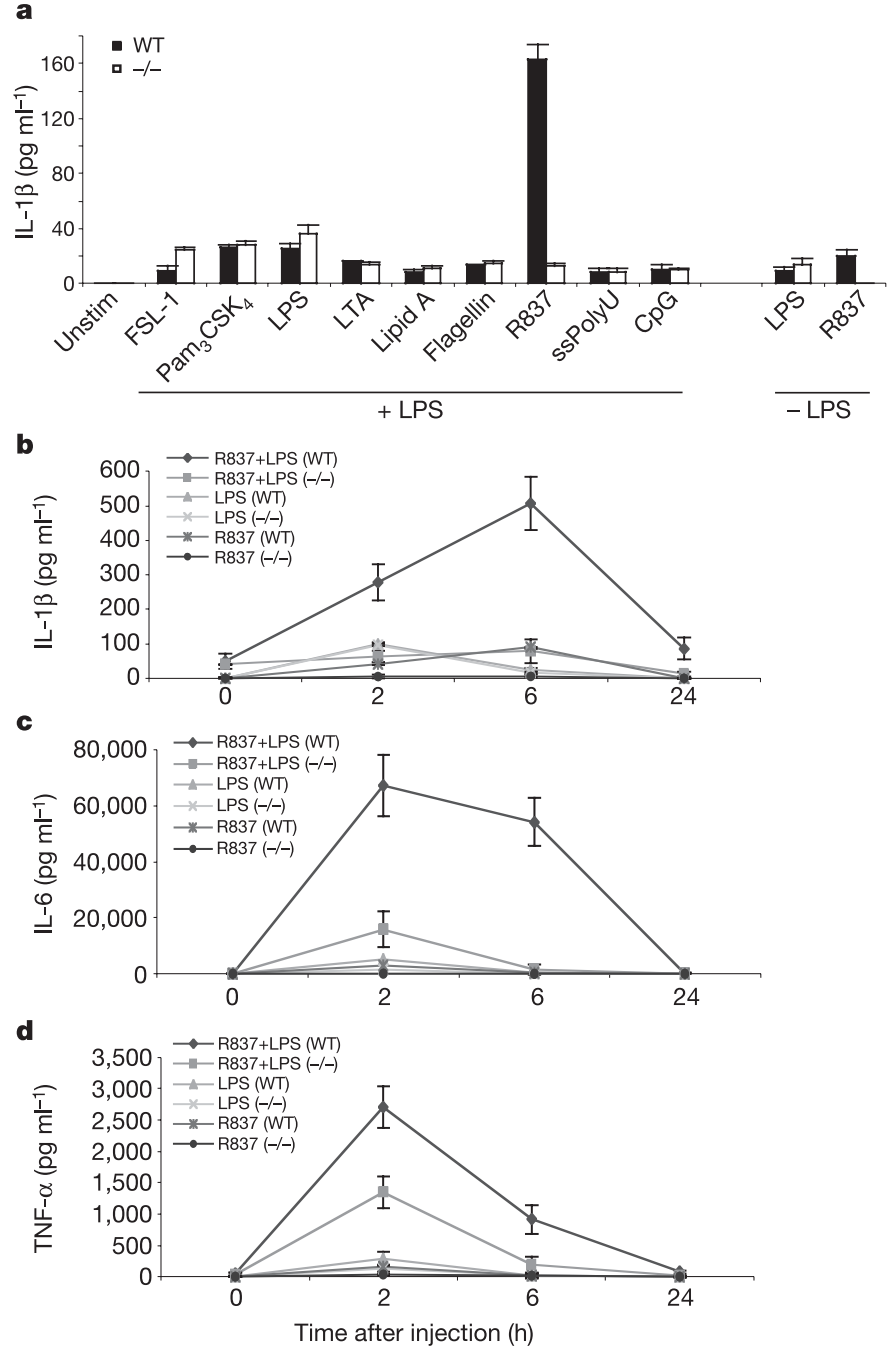

Figure 4 | R837 and LPS cooperate in the production of pro-inflammatory cytokines in a cryopyrin-dependent manner. a, BMDMs from wild-type (WT) or Cias $1^{-l-}$ mice $(-/-)$ were co-stimulated with LPS and the indicated stimuli for $24 \mathrm{~h}$ or left unstimulated (unstim). Cell-free supernatants were analysed by ELISA for IL- $1 \beta$ production. $\mathbf{b}-\mathbf{d}$, Groups of wild-type and Cias1 ${ }^{-1-}$ mice ( $n=7$ mice per group) were co-injected with LPS $(200 \mu \mathrm{g}), \mathrm{R} 837(200 \mu \mathrm{g})$ or LPS plus R837 (200 $\mu \mathrm{g}$ each), and levels of IL-1 $\beta$ (b), IL-6 (c) or TNF- $\alpha$ (d) in serum were determined by ELISA at the indicated times. Error bars represent standard deviation of serum values.

TLR7/TLR8 discriminate between microbial and endogenous RNA remains poorly understood, but differences in nucleoside modification and the polyA-tail between bacterial and mammalian RNA might be involved ${ }^{19,20}$. R837 and R848 are used as immune response modifiers in the clinic and are being considered as vaccine adjuvants $\mathrm{s}^{21-24}$. The potent adjuvant, antiviral and antitumour activity exerted by the imidazoquinoline compounds could be explained by their ability to activate both TLR and cryopyrin signalling. The identification of cryopyrin as a critical factor for caspase- 1 activation induced by bacterial RNA has implications for host defence and RNA-based vaccines as well as for our understanding of inflammatory diseases.

\section{METHODS}

Mice. Cias1-knockout mice were generated by homologous recombination in embryonic stem cells by replacing exons I and II of the cryopyrin/Cias1 gene (encoding the amino-terminal Pyrin domain) with an IRES- $\beta$-gal-neomycinresistance cassette using a targeting vector (Supplementary Fig. 1). A positive embryonic stem cell clone was used to generate chimaeric mice. 129/C57BL/6 
chimaeric mice were crossed with C57BL/6 females to generate heterozygous mice. Cias1-knockout and wild-type mice were generated by crossing male and female heterozygous mice. Tlr7, Myd88 and Asc knockout mice have been described $^{6,25}$.

Microbial ligands and antibodies. Ultrapure LPS from E. coli 0111:B4 (Invivogen) was used in all experiments. FSL-1, $\mathrm{Pam}_{3} \mathrm{CSK}_{4}$, lipid A, flagellin, R837 and $\mathrm{CpG}$ oligonucleotide were purchased from Invivogen and muramyl dipeptide was purchased from Bachem. Purified total RNA from E. coli and mouse liver was purchased from Ambion. Total RNA from L. pneumophila and L. monocytogenes was prepared using a RiboPure-bacteria kit (Ambion) and RNase (Novagen). The 260/280 absorbance of RNA was 1.7/2. Rabbit anti-mouse caspase-1 and anti-cryopyrin antibodies have been previously described ${ }^{12,26}$. Antibodies against mouse Ік-B $\alpha$, phospho-Ік-B $\alpha$, p38 and phospho-p38 were from Cell Signalling. Western blotting. For analysis of caspase-1 activation, macrophages were cultured with ligands for $1-3 \mathrm{~h}$ and then with medium containing $5 \mathrm{mM}$ ATP (Sigma) for $30 \mathrm{~min}$. Extracts were prepared, transferred to nitrocellulose membranes and immunoblotted with primary antibodies, and then proteins were detected by enhanced chemiluminescence as previously described ${ }^{27}$.

Measurements of cytokines. BMDMs and peritoneal macrophages were prepared as described ${ }^{25}$. Cells were stimulated with various microbial and synthetic ligands for $24 \mathrm{~h}$, and supernatants were analysed for IL-1 $\beta$, IL-18, TNF- $\alpha$ and IL-6 secretion. FSL-1, $\mathrm{Pam}_{3} \mathrm{CSK}_{4}$, LPS, lipoteichoic acid, lipid A and MDP were used at $1 \mu \mathrm{g} \mathrm{ml}^{-1}$. For analysis of the cooperation between LPS and various ligands, $10 \mathrm{ng} \mathrm{ml}^{-1}$ LPS and $10 \mathrm{ng} \mathrm{ml}^{-1}$ of ligand were used. Mouse cytokines were measured in culture supernatants using enzyme-linked immunoabsorbent assay (ELISA) kits from R\&D Systems.

Received 9 October; accepted 12 December 2005.

Published online 11 January 2006.

1. Stojanov, S. \& Kastner, D. L. Familial autoinflammatory diseases: genetics, pathogenesis and treatment. Curr. Opin. Rheumatol. 17, 586-599 (2005).

2. Inohara, N., Chamaillard, M., McDonald, C. \& Nunez, G. NOD-LRR proteins: role in host-microbial interactions and inflammatory disease. Annu. Rev. Biochem. 74, 355-383 (2005).

3. Athman, R. \& Philpott, D. Innate immunity via Toll-like receptors and Nod proteins. Curr. Opin. Microbiol. 7, 25-32 (2004).

4. Agostini, L. et al. NALP3 forms an IL-13-processing inflammasome with increased activity in Muckle-Wells autoinflammatory disorder. Immunity 20, 319-325 (2004).

5. Perregaux, D. G., McNiff, P., Laliberte, R., Conklyn, M. \& Gabel, C. A. ATP acts as an agonist to promote stimulus-induced secretion of IL-1 $1 \beta$ and IL-18 in human blood. J. Immunol. 165, 4615-4623 (2000).

6. Hemmi, H. et al. Small anti-viral compounds activate immune cells via the TLRT MyD88-dependent signaling pathway. Nature Immunol. 3, 196-200 (2002).

7. Jurk, M. et al. Human TLR7 or TLR8 independently confer responsiveness to the antiviral compound R-848. Nature Immunol. 3, 499 (2002).

8. Dinarello, C. A. Interleukin-1 $\beta$, interleukin-18, and the interleukin-1 $\beta$ converting enzyme. Ann. NY Acad. Sci. 856, 1-11 (1998)

9. Dowds, T. A., Masumoto, J., Zhu, L., Inohara, N. \& Nunez, G. Cryopyrininduced interleukin $1 \beta$ secretion in monocytic cells: enhanced activity of disease-associated mutants and requirement for ASC. J. Biol. Chem. 279, 21924-21928 (2004)

10. Dockrell, D. H. \& Kinghorn, G. R. Imiquimod and resiquimod as novel immunomodulators. J. Antimicrob. Chemother. 48, 751-755 (2001).

11. Janssen, R., Verhard, E., Lankester, A., Ten Cate, R. \& van Dissel, J. T. Enhanced interleukin-1 $\beta$ and interleukin-18 release in a patient with chronic infantile neurologic, cutaneous, articular syndrome. Arthritis Rheum. 50, 3329-3333 (2004).

12. O'Connor, W. Jr, Harton, J. A., Zhu, X., Linhoff, M. W. \& Ting, J. P. Cutting edge: CIAS1/cryopyrin/PYPAF1/NALP3/CATERPILLER 1.1 is an inducible inflammatory mediator with NF-KB suppressive properties. J. Immunol. 171, 6329-6333 (2003).

13. Netea, M. G., Kullberg, B. J., Verschueren, I. \& Van Der Meer, J. W. Interleukin18 induces production of proinflammatory cytokines in mice: no intermediate role for the cytokines of the tumour necrosis factor family and interleukin-1 $1 \beta$. Eur. J. Immunol. 30, 3057-3060 (2000).

14. Martinon, F., Agostini, L., Meylan, E. \& Tschopp, J. Identification of bacterial muramyl dipeptide as activator of the NALP3/cryopyrin inflammasome. Curr. Biol. 14, 1929-1934 (2004)

15. Kobayashi, K. S. et al. Nod2-dependent regulation of innate and adaptive immunity in the intestinal tract. Science 307, 731-734 (2005).

16. Heil, F. et al. Species-specific recognition of single-stranded RNA via toll-like receptor 7 and 8. Science 303, 1526-1529 (2004).

17. Lund, J. M. et al. Recognition of single-stranded RNA viruses by Toll-like receptor 7. Proc. Natl Acad. Sci. USA 101, 5598-5603 (2004).

18. Diebold, S. S., Kaisho, T., Hemmi, H., Akira, S. \& Reis e Sousa, C. Innate antiviral responses by means of TLR7-mediated recognition of single-stranded RNA. Science 303, 1529-1531 (2004).

19. Kariko, K., Buckstein, M., Ni, H. \& Weissman, D. Suppression of RNA recognition by toll-like receptors: the impact of nucleoside modification and the evolutionary origin of RNA. Immunity 23, 165-175 (2005).

20. Koski, G. K. et al. Cutting edge: innate immune system discriminates between RNA containing bacterial versus eukaryotic structural features that prime for high-level IL-12 secretion by dendritic cells. J. Immunol. 172, 3989-3993 (2004)

21. Craft, N. et al. The TLR7 agonist imiquimod enhances the anti-melanoma effects of a recombinant Listeria monocytogenes vaccine. J. Immunol. 175, 1983-1990 (2005).

22. Harrison, C. J., Jenski, L., Voychehovski, T. \& Bernstein, D. I. Modification of immunological responses and clinical disease during topical R-837 treatment of genital HSV-2 infection. Antiviral Res. 10, 209-223 (1988).

23. Tomai, M. A. et al. Immunomodulating and antiviral activities of the imidazoquinoline S-28463. Antiviral Res. 28, 253-264 (1995).

24. Marks, R. et al. Imiquimod $5 \%$ cream in the treatment of superficial basal cell carcinoma: results of a multicenter 6-week dose-response trial. J. Am. Acad. Dermatol. 44, 807-813 (2001).

25. Özören, N. et al. Distinct roles of TLR2 and the adaptor ASC in IL-13/IL-18 secretion and host defense against Listeria monocytogenes. J. Immunol. (submitted).

26. Lamkanfi, M., Kalai, M., Saelens, X., Declercq, W. \& Vandenabeele, P. Caspase-1 activates nuclear factor of the $\kappa$-enhancer in B cells independently of its enzymatic activity. J. Biol. Chem. 279, 24785-24793 (2004).

27. Mariathasan, S. et al. Differential activation of the inflammasome by caspase-1 adaptors ASC and Ipaf. Nature 430, 213-218 (2004).

Supplementary Information is linked to the online version of the paper at www.nature.com/nature.

Acknowledgements We thank D. Golenbock and P. Lin for providing mouse bone marrow, S. Bauer for the gift of R848, and J. Ting for anti-cryopyrin antibody. We thank C. McDonald and N. Inohara for discussions and advice, and the Cellular Immunology Core Facility of the University of Michigan Cancer Center for technical support. This work was supported by grants from the National Institutes of Health to G.N. T.-D.K. is supported by an NIH training grant. L.F. is the recipient of a postdoctoral fellowship from the Fondazione Italiana Ricerca sul Cancro. M.B.-M. is supported by a postdoctoral fellowship from the Fondation pour la Recherche Medicale.

Author Information Reprints and permissions information is available at npg.nature.com/reprintsandpermissions. The authors declare no competing financial interests. Correspondence and requests for materials should be addressed to G.N. (bclx@med.umich.edu). 